WSRC-TR-2004-00439

September 2004

WSRC-TR-2004-00439

\title{
Use of the Hazard Prediction and Assessment Capability (HPAC) at the Savannah River Site (U)
}

Westinghouse Savannah River Company Savannah River Site

Aiken, SC 29808

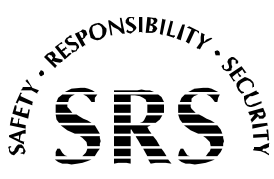


This document was prepared in conjunction with work accomplished under Contract No. DE-AC09-96SR18500 with the U. S. Department of Energy.

\section{DISCLAIMER}

This report was prepared as an account of work sponsored by an agency of the United States Government. Neither the United States Government nor any agency thereof, nor any of their employees, makes any warranty, express or implied, or assumes any legal liability or responsibility for the accuracy, completeness, or usefulness of any information, apparatus, product or process disclosed, or represents that its use would not infringe privately owned rights. Reference herein to any specific commercial product, process or service by trade name, trademark, manufacturer, or otherwise does not necessarily constitute or imply its endorsement, recommendation, or favoring by the United States Government or any agency thereof. The views and opinions of authors expressed herein do not necessarily state or reflect those of the United States Government or any agency thereof.

This report has been reproduced directly from the best available copy.

Available for sale to the public, in paper, from: U.S. Department of Commerce, National Technical Information Service, 5285 Port Royal Road, Springfield, VA 22161, phone: (800) 553-6847, fax: (703) 605-6900

email: orders@ntis.fedworld.gov

online ordering: http://www.ntis.gov/help/index.asp

Available electronically at http://www.osti.gov/bridge

Available for a processing fee to U.S. Department of Energy and its contractors, in paper, from: U.S. Department of Energy, Office of Scientific and Technical Information, P.O. Box 62, Oak Ridge, TN 37831-0062,

phone: (865)576-8401,

fax: (865)576-5728

email: $\underline{\text { reports@ adonis.osti.gov }}$ 
This page was intentionally left blank 
WSRC-TR-2004-00439

September 2004

This page intentionally left blank. 


\section{ABSTRACT}

This report provides background information on the implementation of the Hazard Prediction and Assessment Capability (HPAC) software package at the Savannah River Site (SRS) for atmospheric modeling. Developed by the Defense Threat Reduction Agency (DTRA), HPAC is actually a suite of models that allows for various modes of release of radiological, chemical and biological agents, generates interpolated meteorological data fields based on inputted meteorology, and transports the material using a tested transport and diffusion model.

A discussion of meteorological data availability for direct use by HPAC is given, and is important for applications to emergency response. An evaluation of the data input methodology for a release from SRS is examined, as well as an application to the World Trade Center attacks in New York City in September 2001. Benefits of the newer versions of HPAC now in use are then discussed. These include access to more meteorological data sources and improved graphical capabilities. The HPAC software package is another tool to help the Atmospheric Technologies Group (ATG) provide atmospheric transport and dispersion predictions in the event of hazardous atmospheric releases. 
WSRC-TR-2004-00439

September 2004

\section{TABLE OF CONTENTS}

$\begin{array}{ll}\text { I. INTRODUCTION } & 1\end{array}$

$\begin{array}{ll}\text { II. AVAILABLE DATA } & 2\end{array}$

II.A. Previous Efforts 2

$\begin{array}{ll}\text { II.B. Recent Efforts } & 3\end{array}$

II.B.1. Gridded Data 3

II.B.2. Observed Data $\quad 4$

III. EVALUATION OF INPUT FIELDS

IV. APPLICATION TO 9/11/2001 6

$\begin{array}{ll}\text { V. DISCUSSIONS/CONCLUSIONS } & 7\end{array}$

$\begin{array}{lr}\text { REFERENCES } & 9\end{array}$

$\begin{array}{ll}\text { APPENDICES } & 10\end{array}$

A. Scripts to Download MDS Data for Direct HPAC Use 10

B. General Guidelines to Input Proper Weather Data 11 
WSRC-TR-2004-00439

September 2004

LIST OF TABLES

Table 1: Gridded Data (NOGAPS) Available for Download from MDS for Direct HPAC Use

\section{LIST OF FIGURES}

Figure 1.: Regions containing gridded data at $1 \mathrm{deg}$ resolution and updated at 12-hr intervals for use in forecast situations within HPAC.

Figure 2: Location of observations in the HPAC-MDS meteorological file. This is for a time period in mid-July 2004

Figure 3: Hourly METAR observations at 6-hr intervals starting 12Z, 01 April 1999.

Figure 4: Surface winds predicted by RAMS at 6-hr intervals starting at 12Z, 01 April 1999. The intensity of the winds is given by color, with red arrows denoting higher speeds and purple arrows denoting slower speeds.

Figure 5: HPAC results based on assumptions given. Use of observed data are given by the images on the left side, while use of simulated data in shown on the right.

Figure 6: Concentration plume at 16Z, 11 September 2001 based on arbitrary source for a continuous release from downtown Manhattan, New York, beginning $13 Z$ (0900 LST). Gray shading denotes urban areas, while roads and county borders are denoted as colored lines. The location of meteorological surface stations is denoted by the boxed letter ' $S$ ' while airport locations are given by the colored squares.

Figure 7: (a) Visible satellite imagery at 17Z, 12 September 2001 over downtown New York. (b) Satellite imagery showing only infrared wavelengths at the same time and location. (c) HPAC simulated plume (arbitrary source) for the same time using surface observations in the northeast U.S. to generate the wind fields.

Figure 8: Results from HPAC (version 4) illustrating the capability to show current meteorological conditions along with transport. This simulation assumes a hypothetical continuous release of $\mathrm{I}^{131}$ from Tokyo, Japan beginning 12Z, 03 August, 2004 and shows integrated total dose one day later. The wind barbs denote winds at 1000 mbar at a time of 12Z, 04 August. 
Figure 9: Results from HPAC (version 4) illustrating the improved mapping capability. This simulation assumes a one-hour release of $\mathrm{Pu}^{238}$ from central SRS and shows total integrated dose four hours later, along with an estimate of affected population. GIS shapefiles were created from existing data for the SRS outline, local streams and lakes, as well as onsite active areas.

Figure 10: Sample HPAC menu for selecting gridded data output. In this example, gridded data for Russia at a timestamp of 12 GMT, 10 August, 2004 has been selected.

Figure 11: Sample HPAC menu for selecting observational data output. In this example, profile information for 12 UTC, 11 August, 2004 and surface data for 02 , 03 UTC, 09 August, 2004 have been selected. 
WSRC-TR-2004-00439

September 2004

\section{Use of the Hazard Prediction and Assessment Capability (HPAC) at the Savannah River Site}

\section{Introduction}

The Atmospheric Technologies Group (ATG) has long been associated with an emergency response capability for the Savannah River Site. The Weather Information and Display (WIND) system, consisting of a series of computers and meteorological towers, is used to provide local meteorological information to a suite of atmospheric dispersion codes (Hunter 1990). ATG has also expanded its emergency response capabilities to address potentially hazardous releases that may occur beyond the Savannah River Site boundaries. One way of providing quick estimates of pollutant dispersion for any location around the globe is through the use of the Hazard Prediction and Assessment Capability (HPAC).

The Hazard Prediction and Assessment Capability is an atmospheric dispersion modeling tool developed for military operations. The Defense Special Weapons Agency (DSWA), and later the Defense Threat Reduction Agency (DTRA) developed this tool to provide quick response to threats from weapons of mass destruction. This has been accomplished by using a suite of programs to read in meteorological data and interpolate it to a user-defined grid, describe in detail the source configuration, and run a transport and diffusion code to generate output in a variety of ways (i.e. concentration, dose, etc.). The main code used within HPAC for transport calculations is the SecondOrder Closure Integrated Puff model (SCIPUFF, Sykes et al. 1993, 1998). SCIPUFF describes diffusion processes using second-order turbulence closure by relating the dispersion rate to velocity fluctuation statistics, and has the added advantage of providing variance in the concentration fields, allowing for a measure of uncertainty in the result.

The ATG uses the HPAC software as another means of providing transport calculations in the event of hazardous atmospheric releases. The original version (v. 2.0, DSWA 1997) as well as updates to this (v. 3.1, DSWA 1997 and v. 3.2 DTRA 1999) contained limited mapping capabilities, but are nevertheless quite useful. Software has been written in ATG to access available observational data (surface and upper-air) and to run HPAC for any global location. In addition, software has been written to reformat data from a mesoscale numerical model used operationally at the SRS for ingestion into HPAC. These efforts are described in the next section.

The most recent versions of the HPAC software package (v. 4.0, v. 4.0.1b, v. 4.0.3, DTRA 2001) contain differences in mapping capabilities from prior versions (v. 3.2 and older). Although the previously discussed ATG code can be modified to use as input into the new HPAC version, it is also worthwhile to utilize the existing software upgrades within HPAC as well. 
WSRC-TR-2004-00439

September 2004

This report discusses the meteorological data available for use in HPAC, as well as the ways in which ATG acquires these data. Verification of the input data for a series of releases from SRS is then discussed, followed by an application to the tragic events surrounding 11 September, 2001, in which transport calculations were made when it was determined aircraft had impacted the World Trade Center (WTC) in Manhattan, New York. Finally, advantages of the newer version of HPAC are discussed.

\section{Available Data}

\section{II.A. Previous Efforts}

A large amount of observational data are available to ATG through Weather Services International (WSI) via a satellite link that provides continuous meteorological data in real-time. Upper-air reports are available twice daily (00 and 12 UTC or Greenwich Mean Time, GMT; also commonly referred to as Zulu, or ' $Z$ ' time) from roughly 1000 stations worldwide, while surface reports come in two different formats. The surface synoptic bulletins, available every 3 hours, contain reports from $\sim 9000$ stations, while the hourly meteorological airways format (METAR) data consists of reports from $\sim 4000$ stations.

The information from these stations is sent in a raw (coded) format to save space and must be decoded to provide the meteorological information necessary for atmospheric transport calculations. Software developed in ATG to decode the observations (Buckley 1999 ) in the form of graphical user interfaces (GUl's) is used to provide a tabular format of the observational data that may be ingested by HPAC. Use of the METAR format provides denser station coverage within the United States and Western Europe, but contains little, if any, information in other parts of the world. Separate interfaces have been developed depending on which type of surface data is required and have been written using the Interactive Data Language (IDL, 2003).

The Regional Atmospheric Modeling System (Pielke et al. 1992) is a prognostic threedimensional primitive equation model that is used primarily to simulate mesoscale situations. A two-way nested grid mechanism permits the use of finer grid resolution, while a terrain-following vertical coordinate system allows for the incorporation of topographical features. . Three-dimensional dynamic initial conditions as well as lateral boundary conditions are obtained using larger-scale numerical weather prediction (NWP) models available from a variety of sources.

There are two primary advantages in utilizing the numerical model data. Regions containing a limited number of observation stations are more adequately described with the regularly-spaced grid system, and forecast information may be fed into the HPAC dispersion model, allowing for predicted plume locations.

Data from RAMS are stored in analysis files at user-prescribed time-intervals (typically 1 hour for 1 or 2 day simulations) which must be accessed on the PC. This has required 
creating a dynamically-linked library (DLL) on the Windows 2000 operating system which allows the IDL software to read the RAMS analysis files. An operational version of RAMS has been implemented for the two-state region of Georgia and South Carolina, centered at SRS, that supplies a 36-hr forecast of the meteorology. The original operational version was a single-grid domain at $20-\mathrm{km}$ horizontal grid spacing, while more recently a nested grid domain with horizontal grids of 30 and $10-\mathrm{km}$ spacing has been implemented. This information may be stored daily after the simulation is completed and accessed using IDL. Scripts may then be set up to automatically process this information to generate files that may be ingested by HPAC.

The RAMS gridded information is contained on a polar-stereographic grid, which must be interpolated to a regular (latitude/longitude) geographical grid. In addition, only a subset of vertical levels is needed.

\section{$\underline{\text { II.B. Recent Efforts }}$}

Recently, ATG acquired access to meteorological data, some of which may be directly ingested by HPAC (v.4.0.1b and newer). These data are both gridded and observed and are available for through the Meteorological Data Server (MDS), a consolidated source of meteorological data also developed by DTRA, requiring a special account to access. ATG has obtained permission to access these data.

\section{II.B.1. Gridded Data}

The gridded data is generated using the Navy Operational Global Atmospheric Prediction System (NOGAPS) provided through the Navy's Fleet Numerical Modeling and Operations Center (FNMOC). The full NOGAPS data covering the entire globe are available in gridded binary (GRIB) format and must be decoded and cast into a format that may be ingested by other codes, such as RAMS or HPAC. Scripts have been written by ATG to do this in an automated fashion.

The data are available globally on a grid with $1^{\circ}$ latitude by $1^{\circ}$ longitude $(\sim 110 \mathrm{~km})$ spacing and 26 pressure levels ranging from 1000 mbar up to $10 \mathrm{mbar}(\sim 30 \mathrm{~km}$ above ground). Note that prior to 2004, NOGAPS data were received regularly by ATG from an alternate source but contained less information. The current retrieval is a significant improvement in vertical resolution over the old NOGAPS data set that contained only 13 vertical levels. The forecast data are available out to 144 hours (6 days), although ATG only accesses these data out to 72 hours. The forecast data are available in 6-hr increments out to 60 hours, and at 12-hr increments thereafter. This is also an improvement over the old data that were only available at 12 -hr increments.

Typically, ATG uses NWP products generated by the National Centers for Environmental Prediction (NCEP) models (as administered by the National Atmospheric and Oceanic Administration, NOAA). NOGAPS represents an alternate data source, and is thus valuable in terms of model evaluation. It is also useful to have access to 
more than one NWP data source in the event one is not available for a particular forecast period.

The MDS also contains gridded data that are subsets of the full NOGAPS data contained on five separate domains and rewritten in a format that HPAC can directly ingest. Grids available for download at 12-hr intervals are given in Table 1 and indicated in Fig. 1. Grid spacing is also 1 degree for each of the domains. There are 20 vertical levels at pressures of $1000,975,950,925,900,850,800,700,500,400,300$, $250,200,150,100,70,50,30,20$, and 10 mbar.

Each file contains $\mathrm{U}, \mathrm{V}$ (east-west and north-south) velocity components ( $\mathrm{m} \mathrm{s}^{-1}$ ), temperature (C), and relative humidity (fraction) for periods up to 48 hours into the future. Assuming $Y Y Y Y$ indicates the year, $M M$ the month, $D D$ the day, and $H H$ the hour (UTC), for a file labeled YYYYMMDDHH, the data available extends from $H H+12$ to $H H+60$ hours.

It is clear from this discussion that the grid resolution typically available through the MDS is much coarser than would be used by a mesoscale model such as RAMS. Thus, the transport effects from hazardous atmospheric releases using these MDS data would be helpful only from a regional or synoptic (100 to $2000 \mathrm{~km})$ perspective, since the meteorology is not resolved at the local scale. However, it should also be noted that data at finer resolution ( 0.2 degrees) in parts of the world are also available through the MDS, but are not available in a consistent manner. These data are generated using the Coupled Ocean/Atmospheric Mesoscale Prediction System (COAMPS), a mesoscale model developed by the Naval Research Laboratory. COAMPS typically uses NOGAPS data for initial and lateral boundary conditions. A capacity to use HPAC on the mesoscale would require pre-determined RAMS or COAMPS simulations for the area of interest (i.e. venues for large sporting events such as the Summer Olympic Games held in Athens, Greece during August 2004).

\section{II.B.2. Observed Data}

The observational data contain surface and upper-air reports covering the globe. For the surface files, data are obtained each hour and contain $~ 3000$ stations consisting of $\mathrm{U}$ and $\mathrm{V}$ velocity components, temperature, relative humidity (\%), and pressure (mbar). For each upper-air file, there are 80 to 100 stations reporting data at mandatory levels, as well as at the surface levels. An example of the available stations (for a mid-July 2004 time period) is shown in Fig. 2. It is evident the bulk of the observations tend to exist within Europe and the United States. It is also clear that the data available through MDS are not as comprehensive as is available through WSI. However, either the gridded or observed MDS data may be easily ingested into HPAC for dispersion and transport use. It should be noted that the format required of observations in the older HPAC versions is slightly different from that of the new HPAC versions. 
WSRC-TR-2004-00439

September 2004

Scripts have been written to automatically download and store the gridded and observational data at MDS and are described in the Appendix A. An example showing proper selection of input meteorological data is described in Appendix B.

\section{Evaluation of Input Fields}

The HPAC graphical user interface allows for many input variables regarding source strength, number, and location. The main purpose of the descriptions contained within this report is to describe how the input weather conditions need to be formatted for use in the model, and the results that may be gained from such an analysis.

For the example illustration provided here, a 24-hr period beginning 12Z, 01 April 1999 is considered. The release location is at the center of the Savannah River Site $\left(33.25^{\circ} \mathrm{N}, 81.625^{\circ} \mathrm{W}\right)$ at $60 \mathrm{~m}$ AGL. The approximate radius of concern is $500 \mathrm{~km}$ from this central location and it is assumed that tritium is released at a constant rate of 1000 $\left(\mathrm{Ci} \mathrm{s}^{-1}\right)$.

Surface observations over the period at 6-hr intervals are illustrated in Fig. 3. Note that roughly 70 surface stations exist within the domain. The center of the domain is marked with an asterisk and the two stations just to the northwest of center are Bush and Daniel fields in Augusta, GA. Using these station reports, winds at SRS are southerly initially, and shift to southwesterly by 18Z, 01 April (Fig. 3b). For the remainder of the period, winds are calm at both Augusta reporting stations. On the whole, winds at the initial time are stronger throughout the region than they are from 00 to 12Z, 02 April 1999.

For simulated surface winds, results from RAMS at 20-km horizontal grid spacing have been used at one-hour intervals. Results showing surface winds over the same time period are given in Fig. 4. According to RAMS, the winds are also initially southerly at $12 Z, 01$ April, shift to southwesterly at $18 Z$ and strengthen, then weaken by $00 Z, 02$ April (Fig. 4c). Winds shift eventually to southerly and light by $06 Z$ (Fig. 4d), and then westerly by 12Z, 02 April. The winds near SRS are very light over the final 12 hours as a shift occurs just after 00Z, 02 April. This shift in surface winds can also be seen in Figs. $4 \mathrm{c}-4 \mathrm{e}$ for station observations along the Atlantic Coast.

Three different releases are simulated for this period: (A) 1-hr continuous release starting at 12Z, 01 April 1999, (B) 1-hr continuous release starting at 18Z, 01 April, and (C) 4-hr continuous release starting at 00Z, 02 April. Plumes resulting from the use of observed winds and temperatures are illustrated in the form of integrated surface concentration at 12Z, 02 April 1999 for each of the three releases (Fig. 5, left-hand side). Plots using the gridded RAMS fields are also shown in Fig. 5 (right-hand side).

For the first release (case A) using observations (Fig. 5a), effluent is released when winds are stronger leading to a narrow plume footprint directed first northward, then veering to the northeast. With the advent of weak or calm winds later during the period, a large area of very weak concentrations is seen to cover the northeastern half of South 
Carolina and parts of North Carolina. Figure 5c (release starting at 18Z) illustrates the plume footprint before winds had become calm across the region. An initially thin plume directed toward the northeast eventually spreads at later times as calmer conditions are encountered. Finally, Fig. 5e shows a plume subjected to light winds throughout the period, resulting in a much smaller area of influence (almost circular in shape) which extends just to the east of SRS.

The simulated wind fields clearly show higher mean wind field strengths over the entire domain. The plume footprint for the 12Z, 01 April release (Fig. 5b) is much narrower and exits the calculation domain to the east-northeast of the release point. A wider dispersal pattern is evident only very late in the release as effluent reaches eastern portions of North Carolina. In addition, it is evident that the predicted winds near the source at the release time were more southwesterly than observed. For the release at 18Z, a narrow plume is initially seen heading to the east-northeast, before getting caught up in southerly flow at lower speeds. This results in a wider dispersal pattern (Fig. 5d), similar to Fig. 5a. The 4-hr release (Fig. 5f) indicates a weakening of advective transport, as with the observations, although the simulated plume covers parts of eastern Georgia, including Augusta.

Clearly, the lack of non-zero observed winds during much of the latter simulation period resulted in a much wider zone of influence in dispersion than that predicted using the RAMS model. If the observations containing calm wind conditions were instead denoted as missing, fewer stations would be accessed and more advective transport (i.e. narrower plumes) would result. This would imply even greater similarities with the RAMS simulation. Nonetheless, general plume footprint patterns between using observations and RAMS simulations are similar, and both indicate the interpolation mechanism within HPAC to generate wind fields appears to work with regard to the input files.

\section{Application to $9 / 11 / 2001$}

An example of the use of this technique in a real situation was realized on 11 and 12 September, 2001. Terrorists crashed jet airplanes into the 'twin towers' of the World Trade Center (WTC) on the morning of 11 September. Observations taken during the event were used to show plume movement in the vicinity of the Trade Centers, and indicated dispersal out into the Atlantic Ocean (Fig. 6). The box surrounding a letter ' $S$ ' in Fig. 6 denotes the location of surface observations used in the interpolation of the wind fields. Roads, urban areas, and airport locations are also shown, but other mapping capabilities were not available in this older version of HPAC.

The Multi-spectral Thermal Imaging (MTI) satellite was used to generate images of the WTC area at 1300 LST (17 GMT), 12 September 2001 (roughly one day after the terrorist attacks). Two images from the MTI satellite are shown in Fig. 7 (a, b). 
The graphic depicting smoke traversing across the Manhattan area (Fig. 7a) is a visible image. The most intense smoke appears to be centered over Manhattan, with less dense smoke traveling westward across the Hudson River and into New Jersey. The graphic containing a bluish area near the attack site (Fig. 7b) is a false color image depicting wavelengths in the infrared (between 2.08 and $5.07 \mu \mathrm{m}$ ) region. This characterization is used because it is sensitive to changes in surface characteristics (i.e. dust or temperature). The white area at "ground-zero" indicates extremely high temperatures and the possible presence of fire.

In order to assess the potential atmospheric consequences of this release, a simulation of the smoke transport using observed meteorology was performed. The release was assumed to be a continuous, arbitrary non-buoyant source 300 meters above ground starting at 0900 LST, 11 September, 2001 and continuing until 1300 LST, 12 September, 2001 (28 hours later).

Winds during and after the attack were from the north-northwest or north sending the plume out across Brooklyn and over the Atlantic Ocean. However, the winds shifted to easterly, then southerly the next day. The simulated graphic (Fig. 7c) shows predicted surface concentrations (pink and red most intense, blue least intense) averaged over the current hour for a time corresponding to the satellite images, after winds had shifted to easterly. The location of the simulated smoke plume agrees quite well with the satellite imagery.

\section{Discussions/Conclusions}

The ability to provide dispersion estimates in the event of accidental atmospheric releases based on both observed and numerically simulated meteorological information is an important part of operations in ATG. Observations may be accessed from any global location over a period of time to provide input for HPAC, which then allows for estimates of the pollutant dispersion. Simulations of weather conditions in three dimensions using RAMS may also be used to provide forecast information provided the domain has been previously selected. The entire operation from accessing the data to providing a quick estimate of the pollutant transport is roughly 2 to 10 minutes. The addition of the NOGAPS data from global locations covering almost all of the northern hemisphere is an obvious benefit.

There are two additional advantages to the new version of HPAC over its predecessor from ATG's perspective. The first advantage is that meteorology can be plotted (either gridded at different pressure levels, or observations at various locations or heights above the ground). An example of this for a release in Japan is shown in Fig. 8. A hypothetical continuous release of ${ }^{131}$ at 1000 Ci per hour from Tokyo, Japan beginning at 12 UTC, 03 August, 2004 is assumed and the plume depicted shows integrated dose after one day. Wind barbs from NOGAPS at 12 UTC, 04 August (at $1000 \mathrm{mbar}$ ) indicate stronger flow over water than over the island of Japan, as expected. Winds over the island near Tokyo are southerly. 
An even more powerful advantage is the capability to accept ArcView Geographic Information System (GIS) shapefiles. The resulting plumes can be overlaid on the detailed mapping as shown by the example given in Fig. 9 . In this instance, a $0.1 \mathrm{Ci}$ per minute release of $\mathrm{Pu}^{238}$ over one hour is assumed from central SRS beginning at $00 \mathrm{Z}$, 21 July 2004. Using observations from the MDS dataset, the plot shows the dose at varying degrees of severity after 4 hours. The level of detail available in the background mapping (i.e. rivers, site boundaries, local roads) was not available in older HPAC versions. For a comparison, see Fig. 5, showing plumes overlaid on maps from HPAC v. 3.2 .

DTRA has also recently worked on incorporating estimates for plume dispersion in urban areas (Pace, 2003). The additions are for exterior dispersion calculations in urban environments. This requires building data for individual cities that have only been generated for a limited number of locations. One urban model available is an empirical Gaussian model derived from wind tunnel experiments that is referred to as the Urban Dispersion Model (UDM). The winds are not actually calculated within the urban setting but rather the dispersion patterns are determined from relationships between wind speed, direction, building data, and dispersion patterns based on the wind tunnel tests. The other option is the Urban Wind Module (UWM), which actually solves the Reynoldsaveraged Navier-Stokes equations using TKE turbulence closure and calculates wind fields by incorporating the building effects. To save on computing time, urban building effects are paramaterized (Pace, 2003). This feature would prove useful in potential accidental (or terrorist) releases in nearly urban settings such as Augusta, Georgia.

In summary, the use of HPAC is important for ATG because it provides a capability to ascertain environmental affects from potential radiological/chemical/biological incidents throughout the Northern Hemisphere within a matter of minutes using three-dimensional and time-varying meteorology. The data are also being archived, and may be used as a means of comparison with data that may be generated by ATG using RAMS. 


\section{References}

Buckley R. L., 1999: Development of Graphical User Interfaces to Visualize Meteorological Data. $15^{\text {th }}$ International Conference on Interactive Information and Processing Systems for Meteorology, Oceanography, and Hydrology, Dallas, TX (January 1999), American Meteorological Society, 474-477.

DSWA, 1997: HPAC, Hazard Prediction and Assessment Capability, Version 2.0, User's Guide, $131 \mathrm{pp}$.

DSWA, 1997: HPAC, Hazard Prediction and Assessment Capability, Version 3.1 User's Guide, 216 pp.

DTRA, 1999: The HPAC User's Guide. Hazard Prediction and Assessment Capability, Version 3.2, $405 \mathrm{pp}$.

DTRA, 2001: The HPAC User's Guide. Hazard Prediction and Assessment Capability, Version 4.0, $605 \mathrm{pp}$.

Hunter C. H., 1990: Weather Information and Display (WIND) system user's manual. WSRC-TM-90-14, Savannah River Site.

IDL, 2003: Interactive Data Language, Version 6.0, Research Systems Inc., Boulder, CO 80301 (www.RSInc.com).

Pace, J., 2003: DTRA Urban Dispersion Modeling Program Update. Presented at the Seventh Annual George Mason University Conference on Transport and Dispersion Modeling, Fairfax, VA (June 17-19, 2003).

Pielke R. A., W. R. Cotton, R. L. Walko, C. J. Tremback, W. A. Lyons, L. D. Grasso, M. E. Nicholls, M. D. Moran, D. A. Wesley, T. J. Lee, and J. H. Copeland, 1992: A comprehensive meteorological modeling system--RAMS. Meteor. Atmos. Phys., 49, 69-91.

Sykes, R. I., S. F. Parker, D. S. Henn, and W. S. Lewellen, 1993: Numerical simulation of ANATEX tracer data using a turbulence closure model for long-range dispersion. J. Appl. Meteor., 32, 929-947.

Sykes, R. I., S. F. Parker, D. S. Henn, C. P. Cerasoli, and L. P. Santos, 1998: PCSCIPUFF version 1.2PD, technical documentation. ARAP Rep. 718, Titan Research and Technology Division, Titan Corp., Princeton, NJ, 172 pp. [Available online at http://www.titan.com/appliedtech/Pages/TRT/pages/scipuff/scipuff_files.htm]. 


\section{Appendix A: Scripts to Download MDS Data for Direct HPAC Use}

Scripts have been written to function on Services for Unix (SFU) to perform a variety of functions.

The current location of the scripts is: ' /cronjobs/FORECASTS/HPAC-DATA', where " $"$ denotes the home directory of the operating system. Using SFU, this generally implies a path such as ' $/ \mathrm{dev} / \mathrm{fs} / \mathrm{D} / \mathrm{SFU}$ '.

getdata-hpac-gridded.scr: Transfers gridded data for the conterminous United States (CONUS), Europe, Russia, Southeast Asia, and Southwest Asia to a current location. This is currently '/dev/fs/D/HPAC4/client/CURRENT'. The filenames are strat_conus_YYYYMMDDHHz.grd, strat_conus_europe_YYYYMMDDHHz.grd, etc. Two days of forecast information is stored at this location. This script is run twice per day ( 04 LST, $\sim 16 \mathrm{LST})$.

getdata-hpac-profile.scr: Transfers profile (upper-air) information for the global locations to the same 'current' location as described above. The filename is raobsglobal-YYYY-MM-DD-HHO0.prf. Two days of profile information is stored at this location. This script is run twice per day ( 08 LST, 20 LST).

getdata-hpac-surface.scr: Transfers surface information for the global locations to the same 'current' location as described above. The filename is sfcobs-global-YYYY$M M-D D-H H 00 . s f c$. Two days of profile information is stored in this location. This script is run 36 minutes past the hour.

blitz.scr: Moves older HPAC meteorological data from the 'current' subdirectory to an archive location, then compresses the files. The archive location is currently on a RAID system:

$/$ dev/fs/H/HPAC-ARCHIVE/GRID for the gridded data, and $/ d e v / f s / H / H P A C-A R C H I V E / O B S$ for the observation data.

This script is run $\sim 18$ LST each day. 


\section{Appendix B: General Guidelines to Input Proper Weather Data}

The following gives general guidelines to using gridded forecast data to simulate the transport and dispersion of effluents using HPAC 4.0.3. Much more detailed information on the use of HPAC is given in the latest user's guide (DTRA, 2001).

+Double-click the shortcut icon on the desktop.

+Either create a new project, or open up an existing one.

+Delete old plots from the map if opening existing plot and it is desired. (View $\rightarrow$ Show Overlay $\rightarrow$ Edit. "Delete" old images)

+Edit the incident, or create new one. (Right mouse click on the incident icon and choose "Edit". For existing project, likely change will only be 'WHEN' it occurs, which will have to match the meteorology date/times available. Note that latest meteorological information if located in /dev/fs/D/HPAC4/client/CURRENT.

+Edit "WEATHER" to match the incident time. (Right mouse click the "WEATHER" icon $\rightarrow$ Modify Weather Datatype $\rightarrow$ Under "Local PC Data", choose "Use Existing HPAC File as is"). You will likely just have to navigate up one directory, then choose 'CURRENT'.

+Select the proper file. (i.e. strat_conus_2004081012z.grd), keeping the mind that the beginning forecast data available in a named file begins 12 hours AFTER the date given in the file name (i.e. for the above file, data available beginning August 11, 00Z). Figure 10 shows which choice to select on the menu, along with an example selection from the file list.

+Make any other changes, then accept.

+ Run, and generate plots as desired.

Note that the above can be done for ANY GLOBAL location where data exists (see Fig. 1).

To use observations only, go to the "WEATHER" editor, and under "Local PC Data", choose the tab labeled "Import Other Files". Again navigate to /dev/fs/D/HPAC4/client/CURRENT. Choose enough observations to bracket the time over which you desire transport calculations (Fig. 11). Depending on how much data you select, saving the processed weather file can take up to one or two minutes. 
WSRC-TR-2004-00439

September 2004

Table 1: Gridded Data (NOGAPS) Available for Download from MDS for Direct HPAC Use

\begin{tabular}{|c|c|c|c|}
\hline Name & $\begin{array}{c}\text { Longitude Range } \\
\left({ }^{\circ} \mathrm{E}\right)\end{array}$ & $\begin{array}{c}\text { Latitude Range } \\
\left({ }^{\circ} \mathrm{N}\right)\end{array}$ & $\begin{array}{c}\text { Horizontal } \\
\text { Grid Points }\end{array}$ \\
\hline CONUS & -180 to -50 & 15 to 72 & $131 \times 58$ \\
\hline Europe & -11 to 50 & 35.5 to 70.5 & $62 \times 36$ \\
\hline Russia & 19 to 180 & 40 to 77 & $162 \times 38$ \\
\hline SW Asia & 9 to 90 & 12 to 42 & $82 \times 31$ \\
\hline SE Asia & 70 to 155 & 5 to 55 & $86 \times 51$ \\
\hline
\end{tabular}


WSRC-TR-2004-00439

September 2004

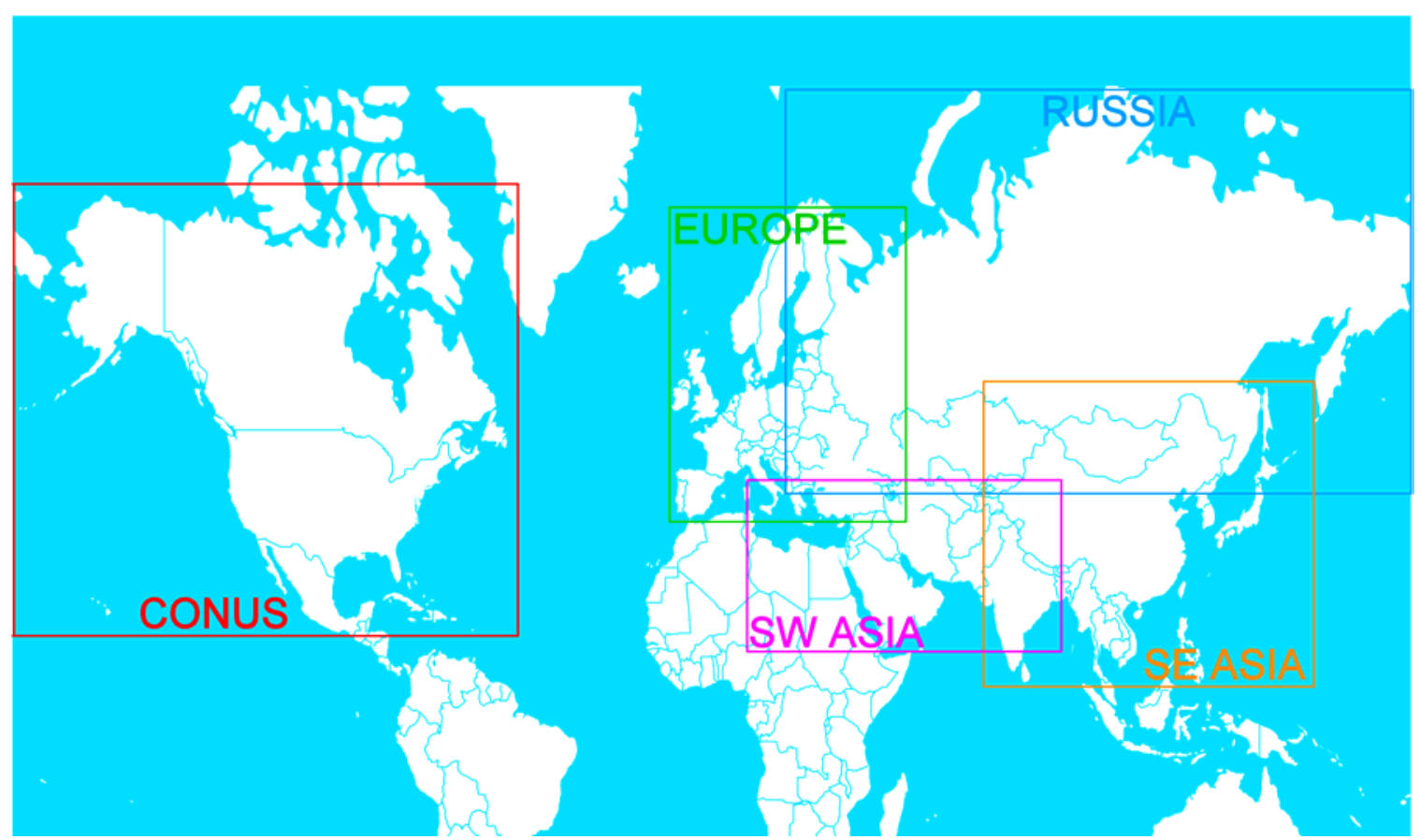

Figure 1: Regions containing gridded data at 1 degree resolution and updated at 12-hr intervals for use in forecast situations within HPAC. 
WSRC-TR-2004-00439

September 2004

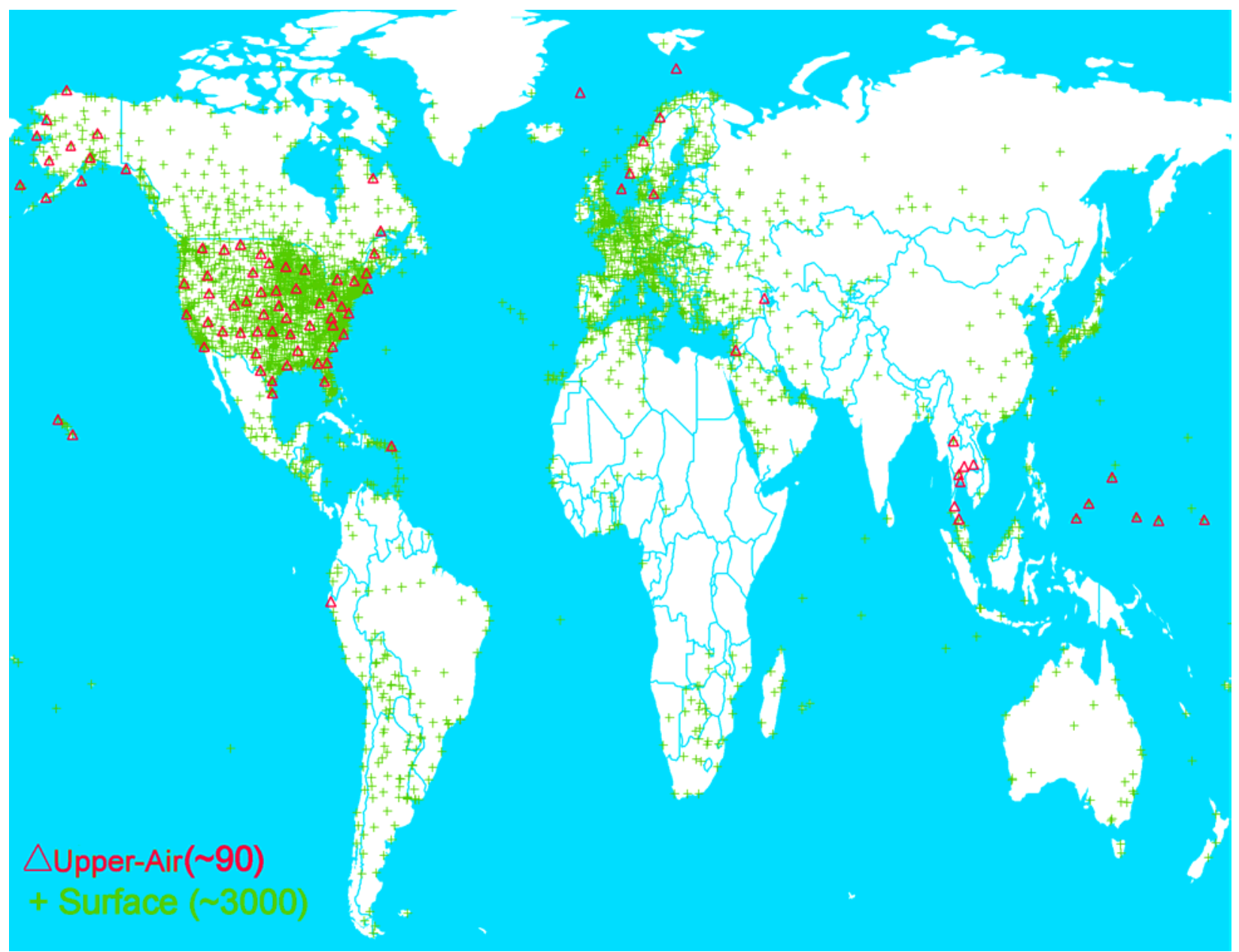

Figure 2: Location of observations in the HPAC-MDS meteorological file. This is for a time period in mid-July 2004. 
(a)

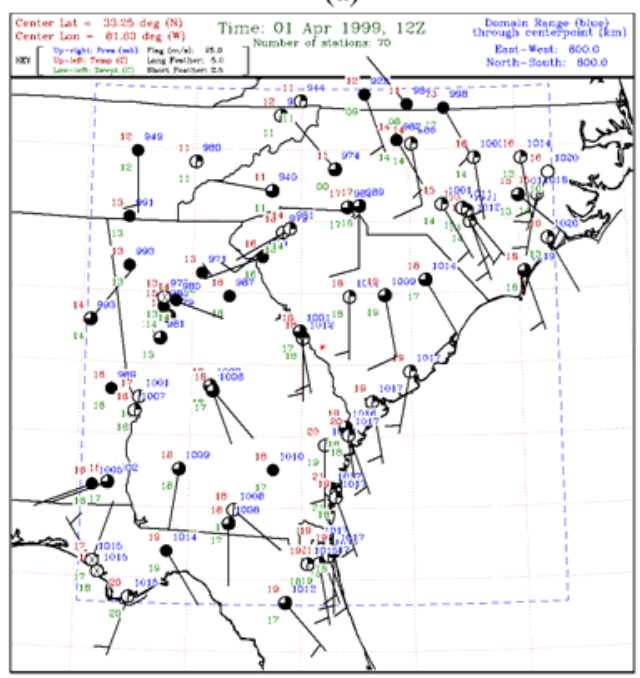

(c)

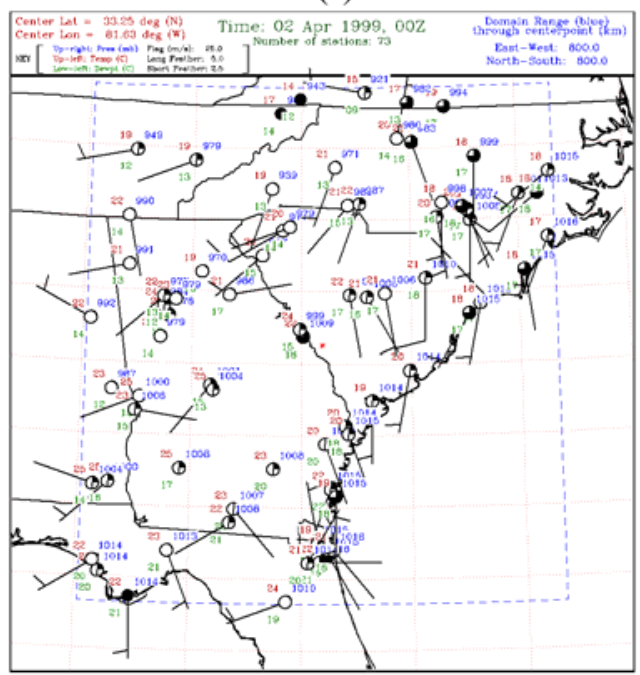

(b)

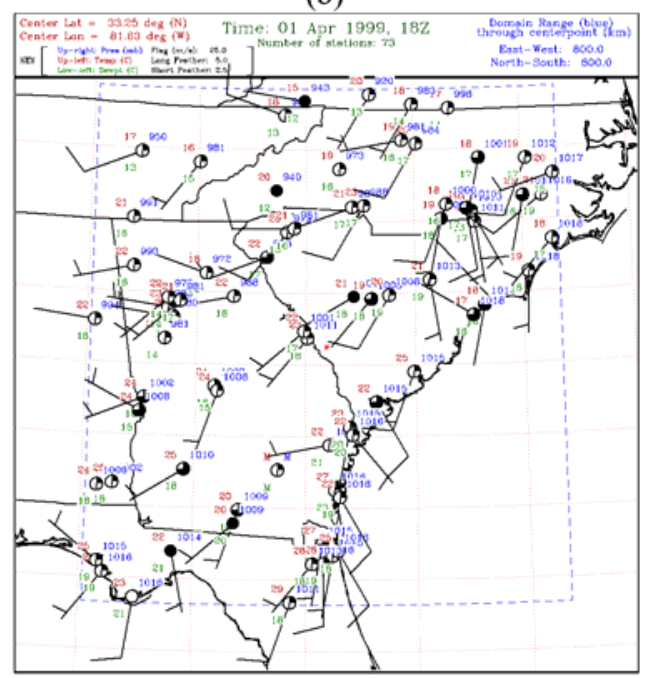

(d)

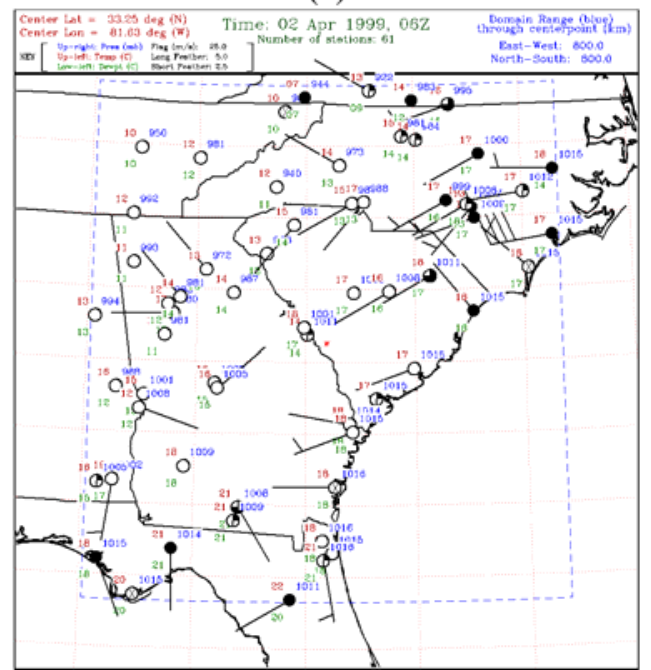

(e)

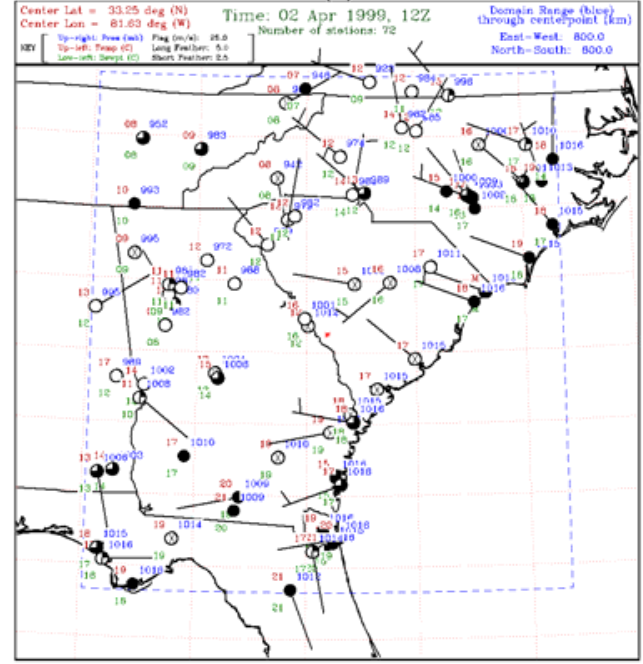

Figure 3: Hourly METAR observations at 6-hr intervals starting 12Z, 01 April 1999. 
(a)

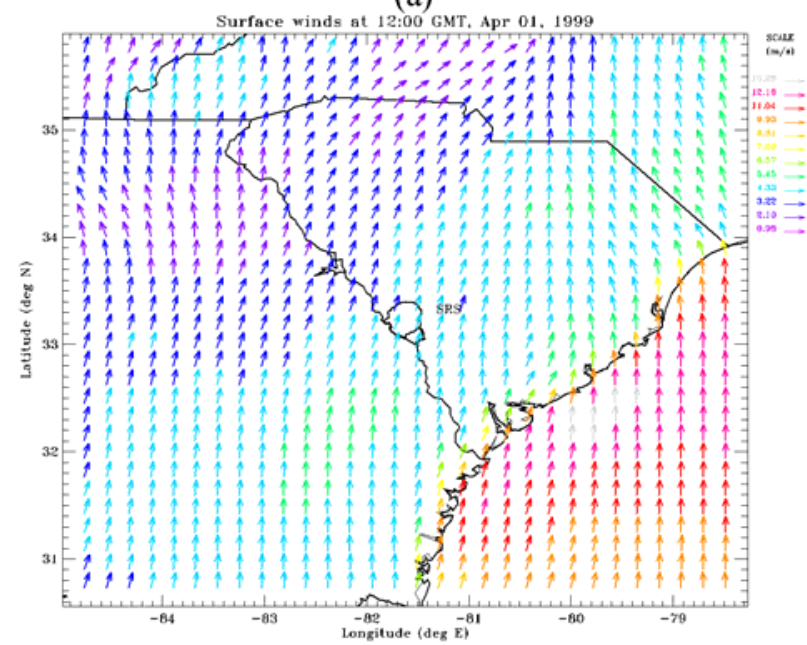

(c)

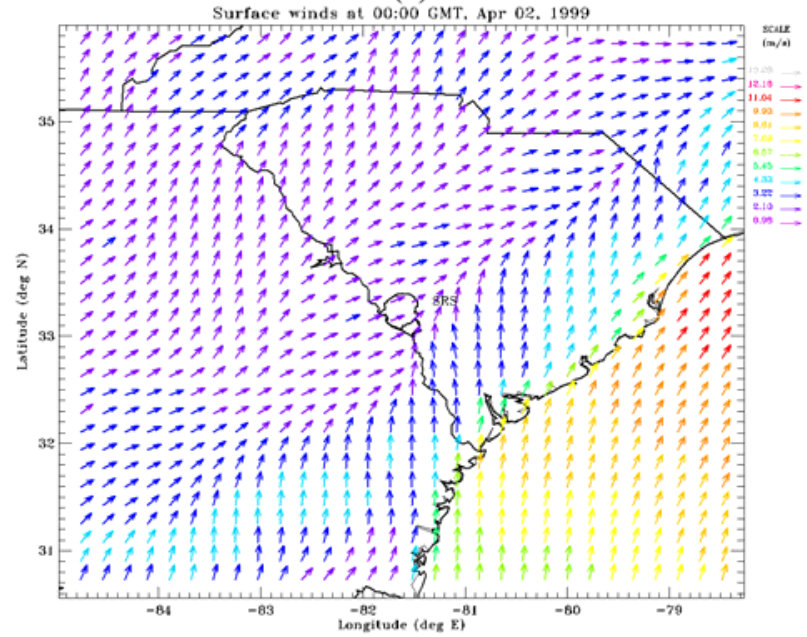

(b)

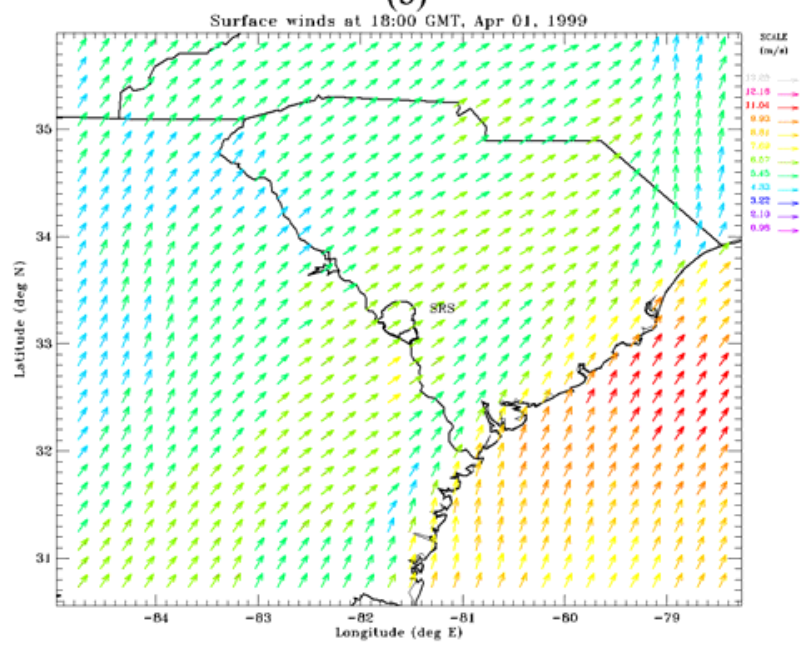

(d)

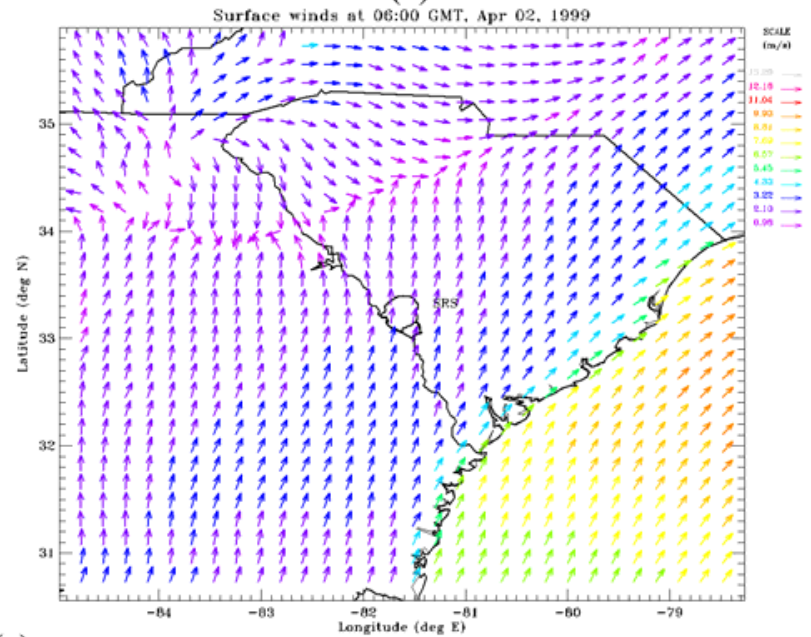

(e)

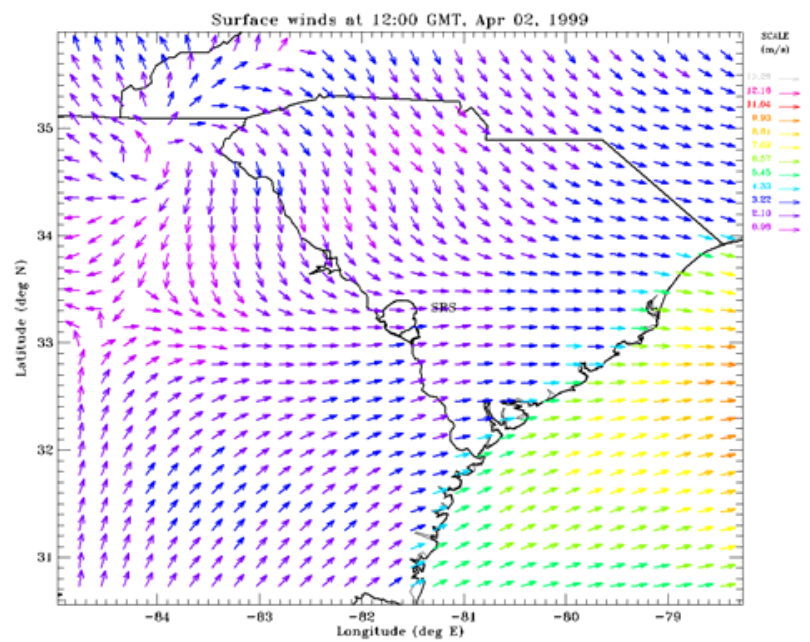

Figure 4: Surface winds predicted by RAMS at 6-hr intervals starting at 12Z, 01 April 1999. The intensity of the winds is given by color, with red arrows denoting higher speeds and purple arrows denoting slower speeds. 
(a)

1-hr release starting 12Z, 01 April 1999 Uses Observed Surface/Upper-air data

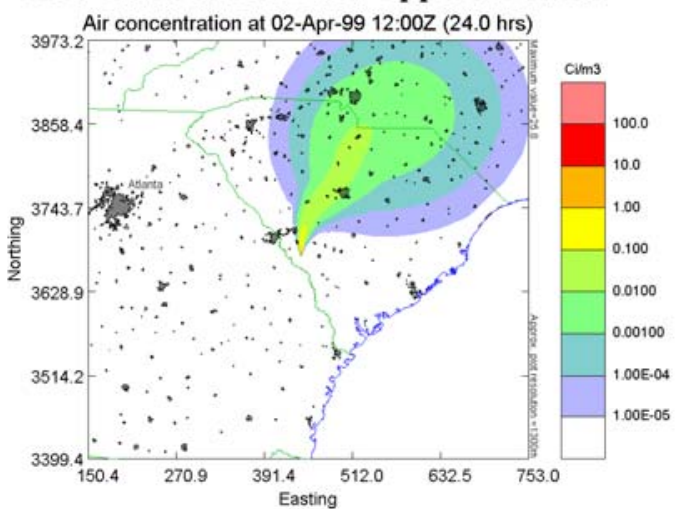

(c)

1-hr release starting 18Z, 01 April 1999 Uses Observed Surface/Upper-air data

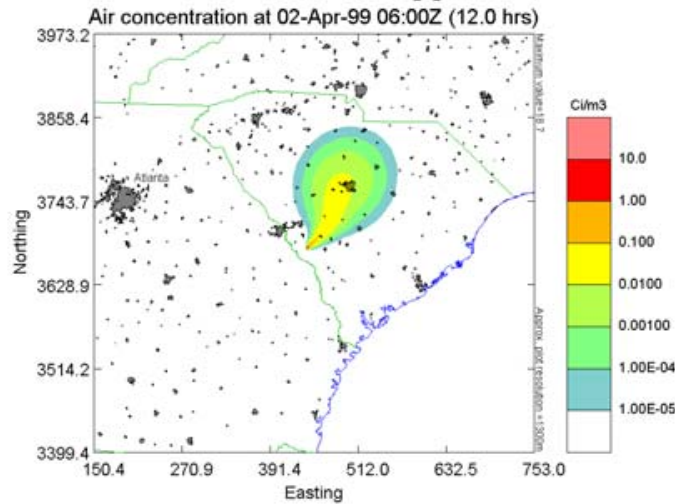

Reteronce zeno: $17 \mathrm{~N}$ (MGS en

(e)

4-hr release starting 00Z, 02 April 1999

Uses Observed Surface/Upper-air data

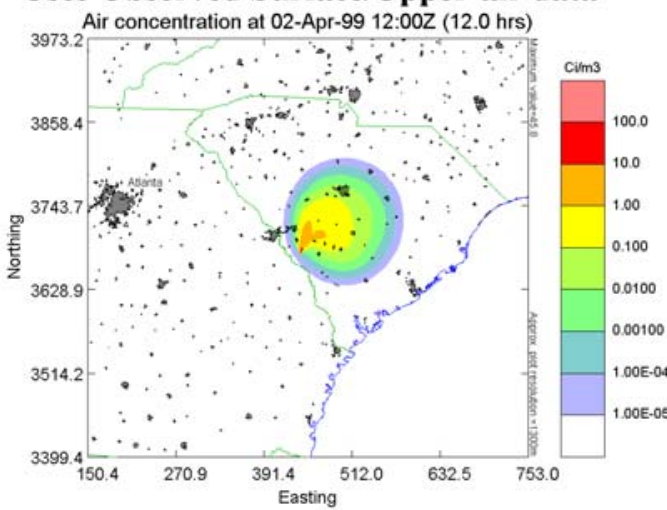

(b)

1-hr release starting 12Z, 01 April 1999

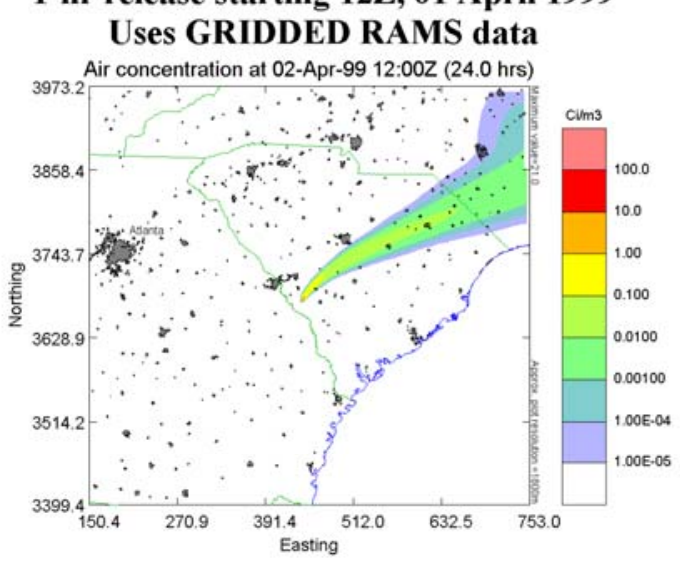

(d)

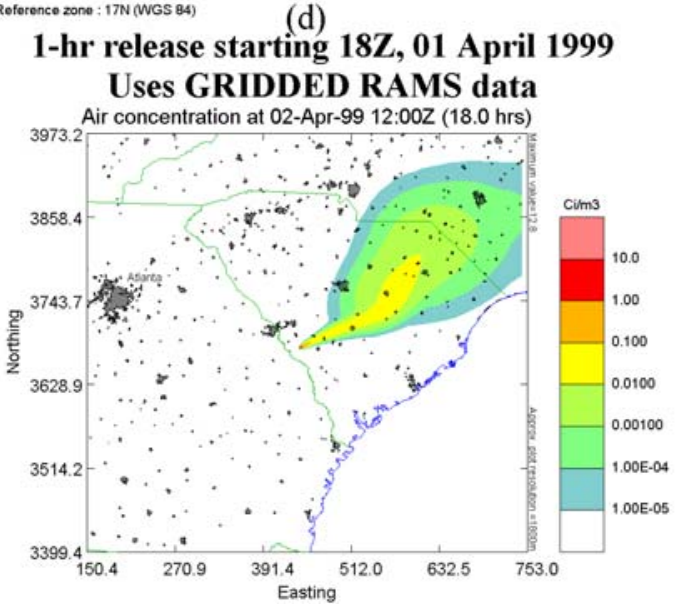

Reference zone : $17 \mathrm{~N}$ (WOS 84 )

(f)

4-hr release starting 00Z, 02 April 1999

Uses GRIDDED RAMS data

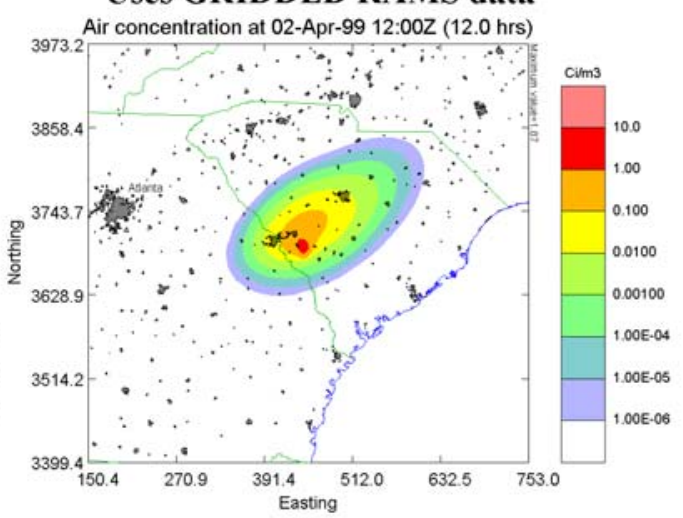

Reference zone : $17 \mathrm{~N}$ (WGS 84)

Reference zone : $17 \mathrm{~N}$ (WGS 84)

Figure 5: HPAC results based on assumptions given. Use of observed data are given by the images on the left side, while use of simulated data in shown on the right. 


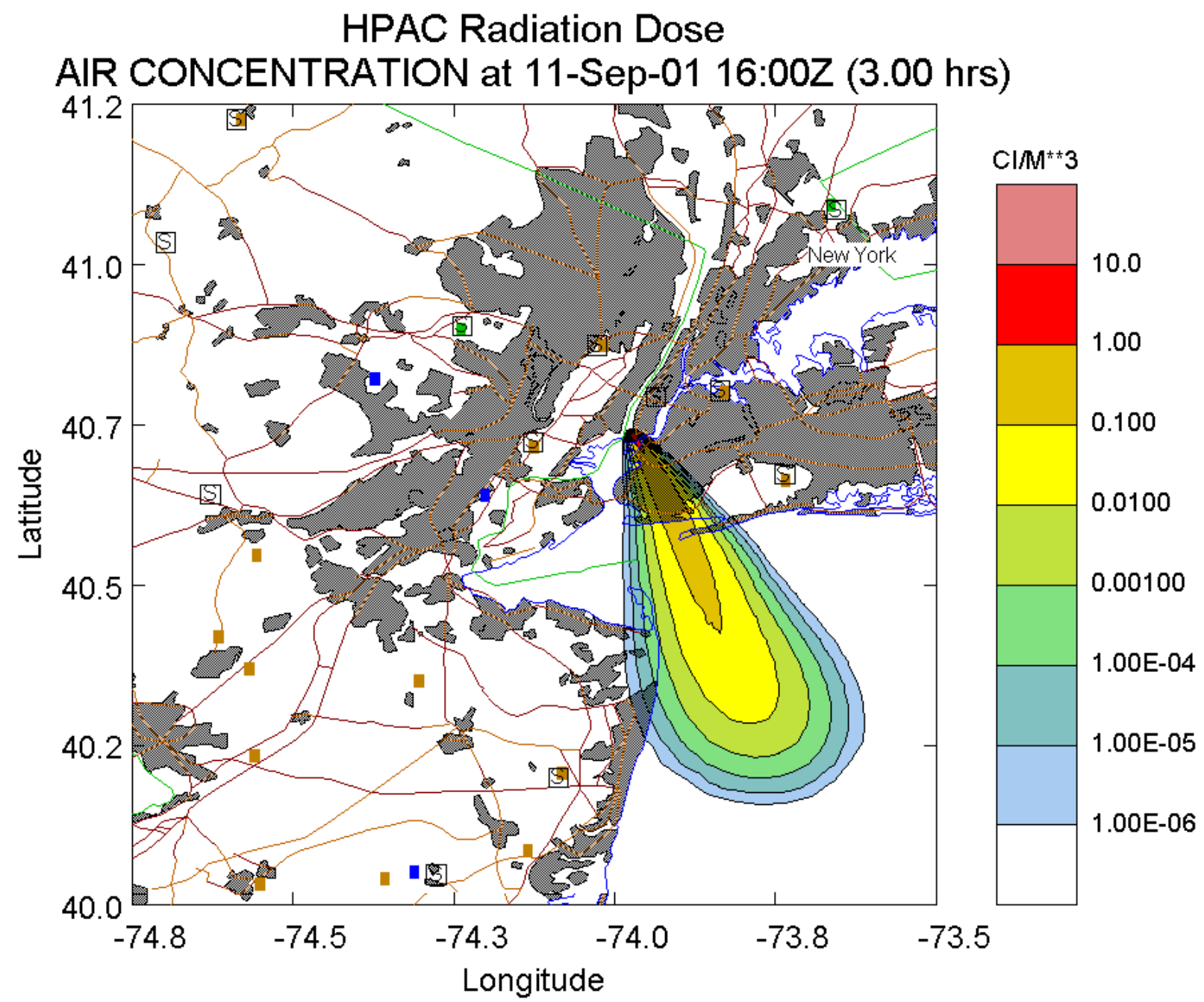

Figure 6: Concentration plume at 16Z, 11 September 2001 based on arbitrary source for a continuous release from downtown Manhattan, New York, beginning $13 Z$ (0900 LST).

Gray shading denotes urban areas, while roads and county borders are denoted as colored lines. The location of meteorological surface stations is denoted by the boxed letter ' $S$ ' while airport locations are given by the colored squares. 
(a)

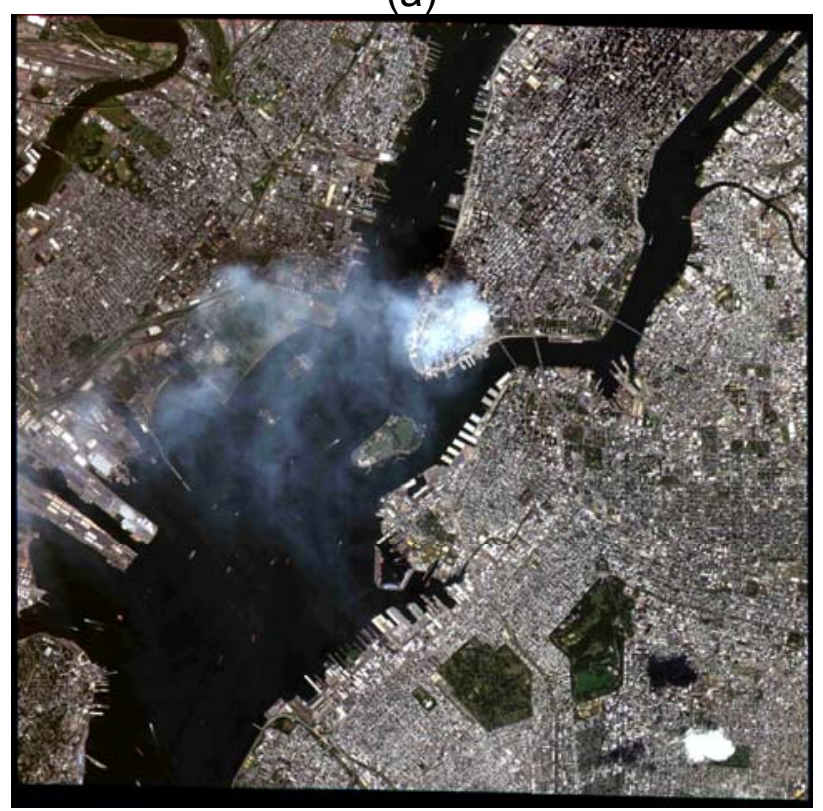

(b)

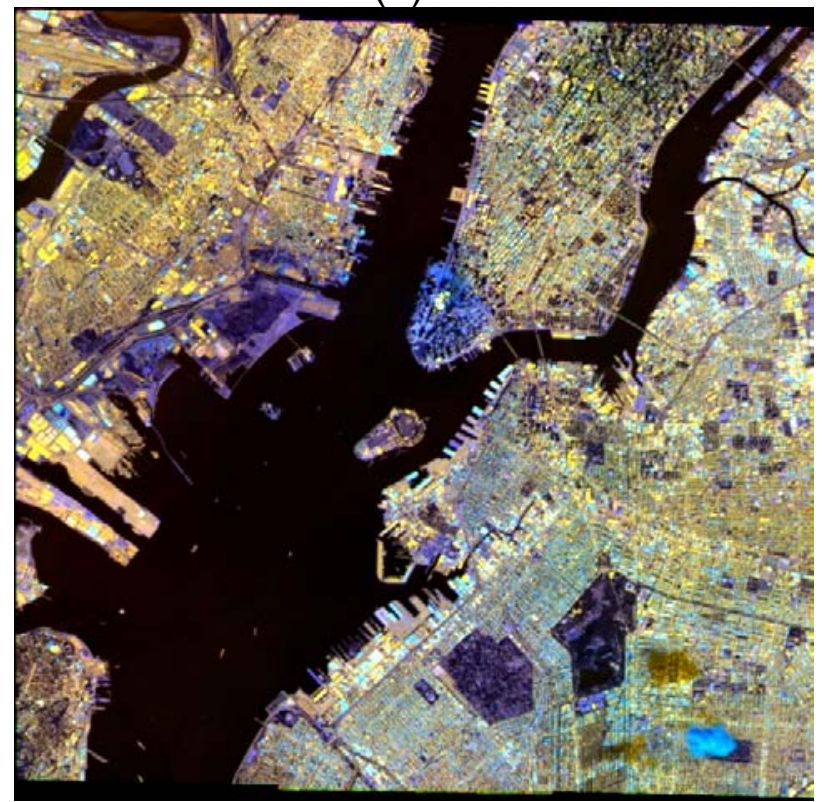

(c)

Horizontal Slice at $z=0.0 \mathrm{~m}$

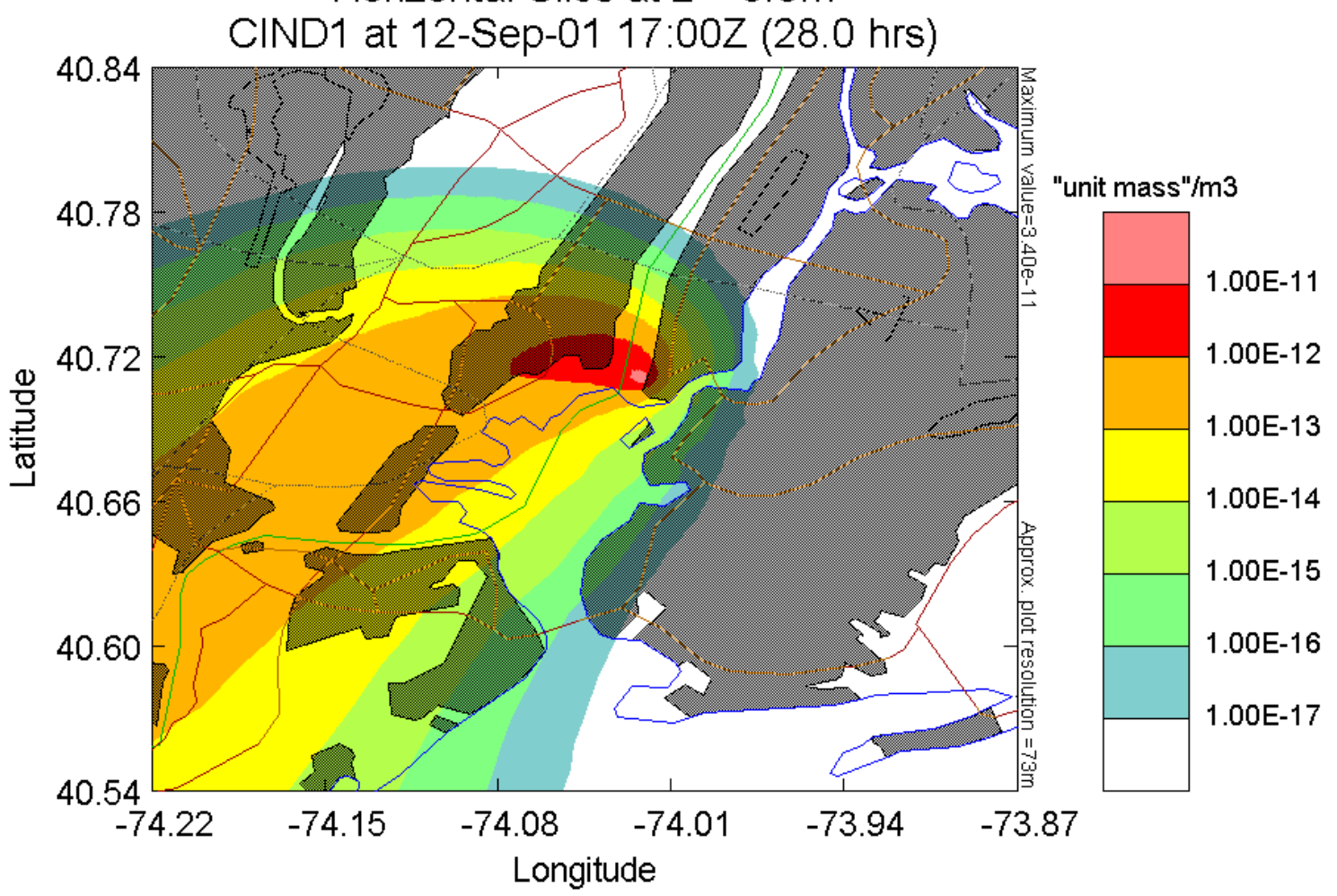

Figure 7: (a) Visible satellite imagery at 17Z, 12 September 2001 over downtown New York. (b) Satellite imagery showing only infrared wavelengths at the same time and location. (c) HPAC simulated plume (arbitrary source) for the same time using surface observations in the northeast U.S. to generate the wind fields. 


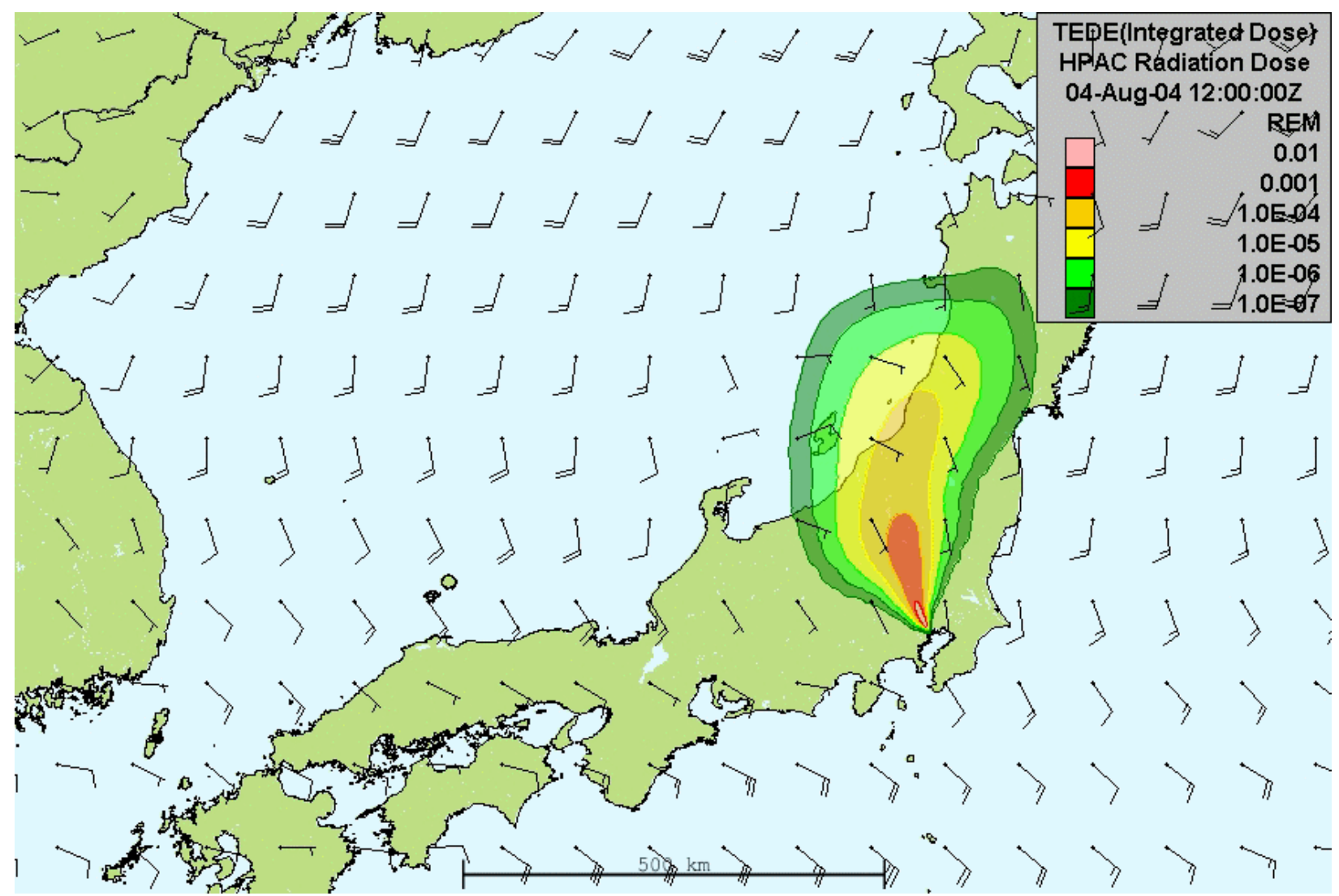

Figure 8: Results from HPAC (version 4) illustrating the capability to show current meteorological conditions along with transport. This simulation assumes a hypothetical continuous release of $I^{131}$ from Tokyo, Japan beginning 12Z, 03 August, 2004 and shows integrated total dose one day later. The wind barbs denote winds at 1000 mbar at a time of 12Z, 04 August. 


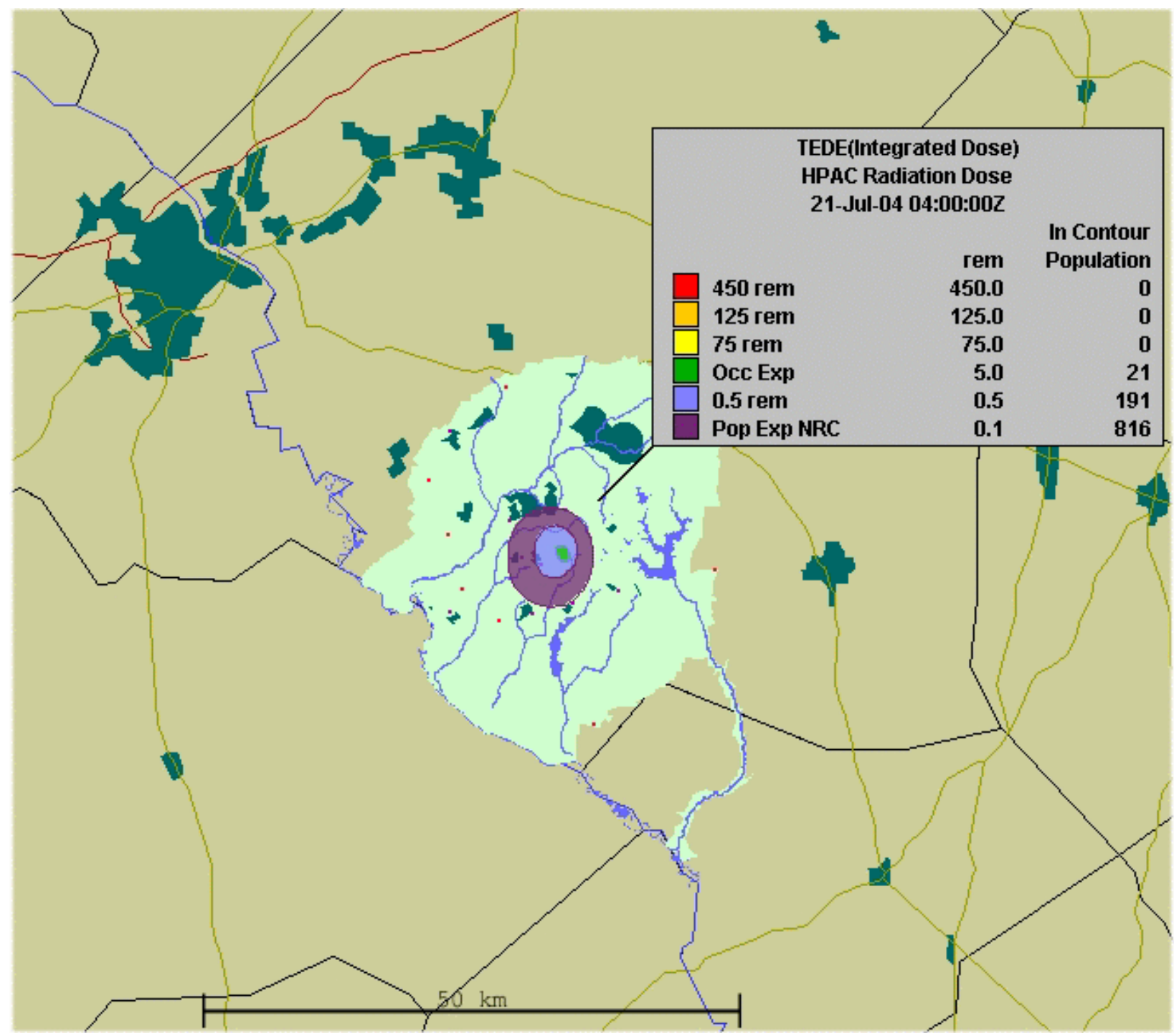

Figure 9: Results from HPAC (version 4) illustrating the improved mapping capability. This simulation assumes a one-hour release of $P u^{238}$ from central SRS and shows total integrated dose four hours later, along with an estimate of affected population. GIS shapefiles were created from existing data for the SRS outline, local streams and lakes, as well as onsite active areas. 
WSRC-TR-2004-00439

September 2004

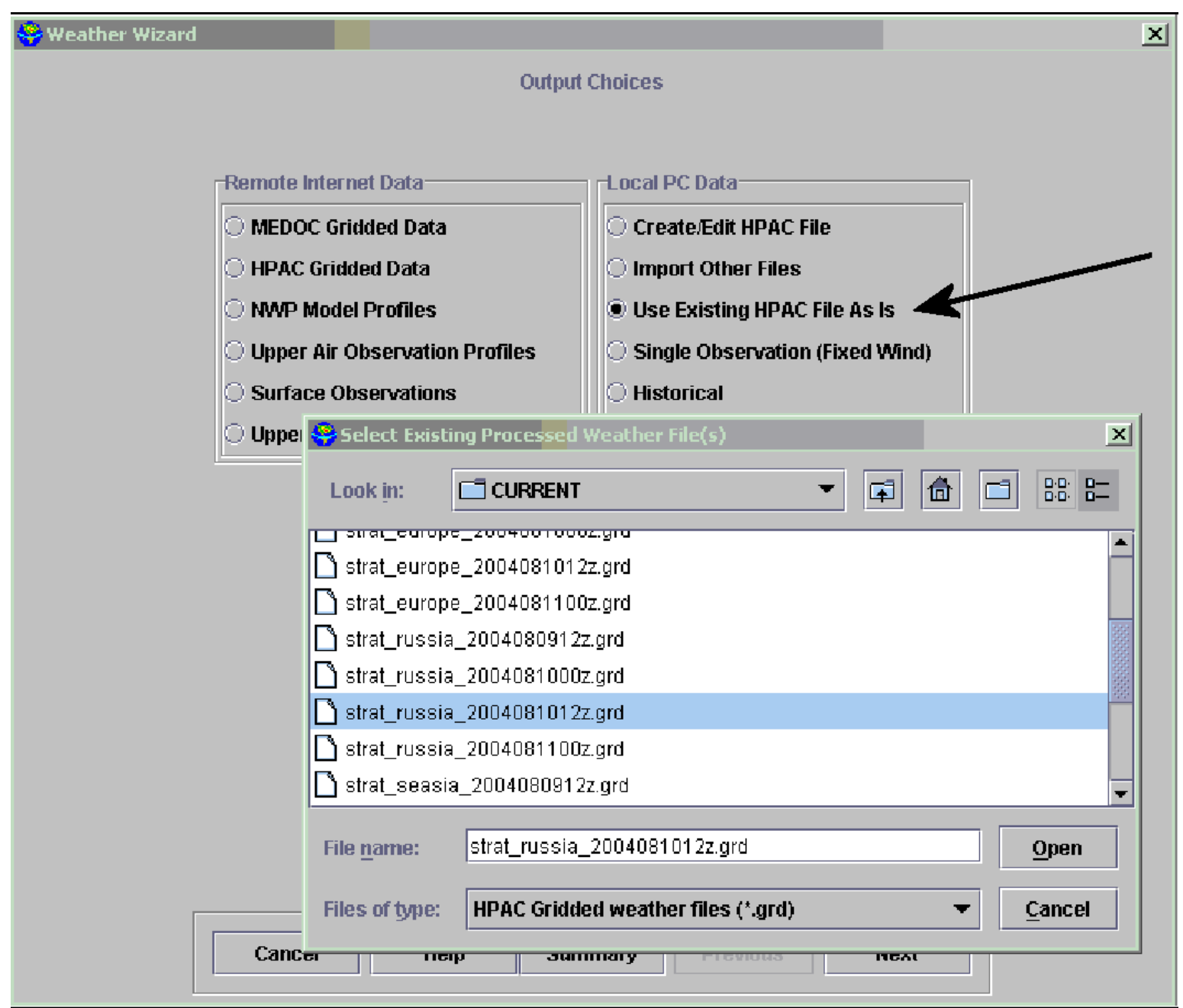

Figure 10: Sample HPAC menu for selecting gridded data output. In this example, gridded data for Russia at a timestamp of 12 GMT, 10 August, 2004 has been selected. 
WSRC-TR-2004-00439

September 2004

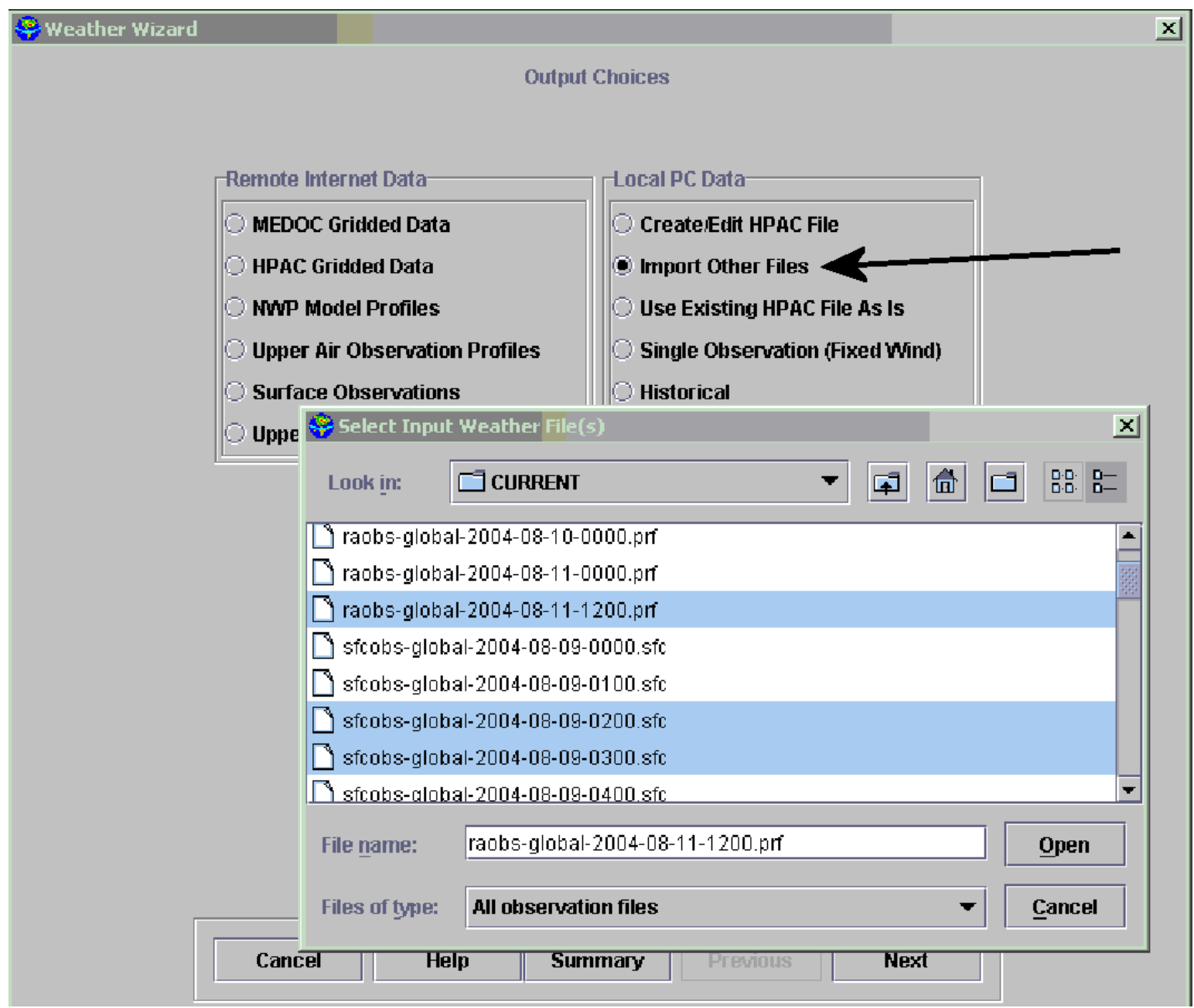

Figure 11: Sample HPAC menu for selecting observational data output. In this example, profile information for 12 UTC, 11 August, 2004 and surface data for 02, 03 UTC, 09 August, 2004 have been selected. 